\title{
openheart Is percutaneous coronary intervention safe during uninterrupted direct oral anticoagulant therapy in patients with atrial fibrillation and acute coronary syndromes?
}

\author{
Leonardo De Luca (D) , ${ }^{1}$ Andrea Rubboli, ${ }^{2}$ Leonardo Bolognese, ${ }^{3}$ \\ Massimo Uguccioni, ${ }^{1}$ Donata Lucci, ${ }^{4}$ Simonetta Blengino, ${ }^{5}$ Jeness Campodonico, ${ }^{6}$ \\ Ilaria Meynet, ${ }^{7}$ Silvia Maria Brach Prever, ${ }^{8}$ Andrea Di Lenarda, ${ }^{9}$ Domenico Gabrielli, ${ }^{1}$ \\ Michele Massimo Gulizia, ${ }^{10}$ MATADOR-PCI Investigators
}

To cite: De Luca L, Rubboli A, Bolognese L, et al. Is percutaneous coronary intervention safe during uninterrupted direct oral anticoagulant therapy in patients with atrial fibrillation and acute coronary

syndromes?. Open Heart 2021;8:e001677. doi:10.1136/ openhrt-2021-001677

Received 4 April 2021 Accepted 14 June 2021
Check for updates

(c) Author(s) (or their employer(s)) 2021. Re-use permitted under CC BY-NC. No commercial re-use. See rights and permissions. Published by BMJ.

For numbered affiliations see end of article.

Correspondence to Dr Leonardo De Luca; leo. deluca@libero.it

\section{ABSTRACT}

Objectives No data on optimal management of patients with acute coronary syndromes (ACS) on long-term direct oral anticoagulants (DOACs) undergoing percutaneous coronary intervention $(\mathrm{PCl})$ are available. Using the data of the Management of Antithrombotic TherApy in Patients with Chronic or DevelOping AtRial Fibrillation During Hospitalization for PCl study, we sought to compare the outcome of patients with ACS and atrial fibrillation (AF) who underwent PCI during uninterrupted DOAC (UDOAC group) and those who interrupted DOAC before PCI (IDOAC group).

Methods The primary outcomes of our analysis were the incidence of major adverse cardiovascular events (MACEs), a composite of death, cerebrovascular events, recurrent myocardial infarction or revascularisation and net adverse clinical events (NACEs), including major bleeding, at 6 months. Results Among the 132 patients on long-term DOAC, 72 (54.6\%) underwent PCI during UDOAC and 60 (45.4\%) after IDOAC. The mean $\mathrm{CHA}_{2} \mathrm{DS}_{2}$-VASc score was $3.8 \pm 1.7$ and $3.9 \pm 1.3(p=0.89)$, while the HAS-BLED score was $2.5 \pm 1.0$ and $2.5 \pm 0.9$ ( $p=0.96)$, in UDOAC and IDOAC groups, respectively. The median time from hospital admission to PCI was 9.5 (IQR: 2.0-31.5) hours in UDOAC and 45.5 (IQR: $22-5-92.0)$ hours in IDOAC group $(p<0.0001)$. A radial approach was used in $92 \%$, and a drug-eluting stent was implanted in $98 \%$ of patients. At 6 months, the rates of MACE $(13.9 \%$ vs $16.7 \%)$ and NACE ( $20.8 \%$ vs $21.7 \%$ ) did not differ between UDOAC and IDOAC groups. At multivariable analysis, increasing $\mathrm{CHA}_{2} \mathrm{DS}_{2}$-VASc score (HR: $1.39 ; 95 \%$ Cls 1.05 to $1.83 ; p=0.02$ ) resulted as the only independent predictor of NACE.

Conclusions Our study shows that $\mathrm{PCI}$ is a safe procedure during UDOAC in patients with concomitant ACS and $\mathrm{AF}$.

\section{INTRODUCTION}

The management of patients on oral anticoagulation therapy requiring percutaneous coronary intervention (PCI) represents a

\section{Key questions}

What is already known about this subject?

- Evidence on the safety of percutaneous coronary intervention (PCI) during uninterrupted direct oral anticoagulation (UDOAC) is scarce, and the opinion on the plausibility of discontinuing the therapy, especially if performed in patients with acute coronary syndromes (ACSs), is conflicting.

What does this study add?

Our study shows that $\mathrm{PCl}$ is a safe procedure during UDOAC in patients with concomitant ACS and atrial fibrillation.

How might this impact on clinical practice?

- A strategy of UDOAC before PCI for ACS may reduce hospital stay and costs.

complex issue due to the need for balancing between both thromboembolic and bleeding complications during periprocedural period. ${ }^{1-3}$ Indeed, thromboembolic risk associated with discontinuation of oral anticoagulants and possible bleeding events associated with an uninterrupted anticoagulation strategy challenge the clinician with daily therapeutic choices. ${ }^{1-3}$

Direct oral anticoagulants (DOACs), including dabigatran, apixaban, edoxaban and rivaroxaban, have emerged as leading therapeutic alternatives to vitamin $\mathrm{K}$ antagonists for the prevention of thromboembolic complications in patients with non-valvular atrial fibrillation $(\mathrm{AF}){ }^{4-6}$ DOACs vary substantially in pharmacokinetic properties, including dependence on renal excretion, so duration to interrupt anticoagulation may differ among different agents. In order to 
address these issues, recent expert consensus documents suggested proper timing for DOAC therapy interruption, based on procedural bleeding risk, type of agent and renal function. ${ }^{4-6}$ Despite these recommendations, several studies have been published in recent years suggesting the feasibility of invasive cardiac procedures during uninterrupted DOAC (UDOAC). ${ }^{4-6}$ Nevertheless, the evidence on the safety of PCI during UDOAC is scarce, and the opinion on the plausibility of discontinuing the therapy, especially if performed in patients with acute coronary syndromes (ACS), is conflicting. ${ }^{4-6}$

In this analysis, we sought to compare the outcome of AF patients on long-term DOAC undergoing PCI for an ACS during an UDOAC versus interrupted DOAC (IDOAC) strategy.

\section{METHODS}

This is an analysis of the Management of Antithrombotic TherApy in Patients with Chronic or DevelOping AtRial Fibrillation During Hospitalization for PCI (MATADOR-PCI) study $^{78}$ aimed to assess the antithrombotic management and clinical events of patients with $\mathrm{AF}$ admitted to Italian cardiology intensive care units (CCUs) for an ACS and undergoing PCI with stent implantation.

The design and the main results of the MATADOR-PCI registry have been published previously. ${ }^{78}$ Briefly, the MATADOR-PCI was a prospective, observational, nationwide registry conducted in 76 Italian CCUs between August 2018 and December 2019. All consecutive patients with AF and a confirmed diagnosis of ACS (non-ST elevation-ACS (NSTE-ACS) or ST-elevation myocardial infarction (STEMI) ) undergoing PCI with at least one stent implantation have been included. ${ }^{7}$ A clinical follow-up at 6 months was also planned for all patients.

Patients admitted with a diagnosis of ACS at the time of enrolment but not confirmed during hospitalisation, ACS treated medically, with surgical revascularisation or with percutaneous coronary balloon angioplasty without stent implantation and those not giving informed consent were excluded from the survey. ${ }^{7}$

Data were collected using a web-based, electronic case report form (CRF) with the central database located at the Associazione Nazionale Medici Cardiologi Ospedalieri (ANMCO) Research Center. By using a validation plan, integrated in the data entry software, data were checked for missing or contradictory entries and values out of the normal range.

Data are be available on reasonable request to ANMCO Research Center, Florence.

In this analysis, we considered only patients treated with DOACs at the time of hospital admission and with an estimated glomerular filtration rate (eGFR) $\geq 30 \mathrm{~mL} /$ min, according to the Cockroft-Gault formula. ${ }^{9}$ Therefore, the study cohort was stratified in two groups of patients: (1) those who interrupted the DOAC before PCI, according to the American College of Cardiology (ACC) expert consensus document recommendations (in case of dabigatran: $\geq 24, \geq 36$ and $\geq 48$ hours in presence of eGFR $\geq 8080-50$ and $50-30 \mathrm{~mL} / \mathrm{min}$, respectively; for other DOACs: $\geq 24$ hours irrespective from eGRF) ${ }^{4}$ and (2) those who did not stop the DOAC before PCI.

In these two groups, we compared the rate of major adverse cardiovascular events (MACEs), a composite of death, cerebrovascular events (stroke, transient ischaemic attack and systemic embolism) and recurrent myocardial infarction (MI) or revascularisation, and net adverse clinical events (NACE), including MACE and major bleeding events at 6 months from hospital admission. MI was defined according to the third universal definition of MI. ${ }^{10}$ Stroke was identified as an acute neurological deficit lasting $>24$ hours and affecting the ability to perform daily activities with or without confirmation by imaging techniques. Bleeding events were defined according to the Bleeding Academic Research Consortium (BARC) criteria. ${ }^{11}$ A major bleeding was defined as $\mathrm{BARC} \geq 3$.

\section{Statistical analysis}

Categorical variables were reported as numbers and percentages and compared by $\chi^{2}$ test. Continuous variables were reported as mean and SD, and compared by t-test, if normally distributed, or as median and IQR, and compared by Mann-Withney $\mathrm{U}$ test, if not.

Multivariable analysis (Cox regression) was performed in order to identify the independent predictors of NACE at 6 months, considering the following variables of clinical interest: $\mathrm{CHA}_{2} \mathrm{DS}_{2}$-VASc score (as continuous), type of ACS at discharge (STEMI vs NSTE-ACS), UDOAC versus IDOAC strategy and eGFR $\geq 50$ versus $<50 \mathrm{~mL} / \mathrm{min}$. Kaplan-Meier curves for MACE and NACE at 6 months from hospital admission were produced and compared by log-rank test.

All tests were two sided. A p value $<0.05$ was considered statistically significant. All the analyses were performed with SAS system software, V.9.4.

\section{RESULTS}

Among the 598 consecutive AF patients enrolled in the registry, 132 were on DOAC at hospital admission: 72 $(54.6 \%)$ underwent PCI without pauses in DOAC treatment (UDOAC group) and in the remaining 60 (45.4\%) patients the DOAC was stopped before the procedure (IDOAC group). In this latter group, the median time from the last DOAC assumption to PCI was 24 (IQR: 24-48) hours. The different types and dosages of DOACs in the two groups and the median time intervals from the last DOAC assumption to PCI are detailed in figure 1.

Clinical characteristics of the study population are shown in table 1. Patients in the UDOAC group were significantly younger and presented more frequently a diagnosis of STEMI at discharge compared with patients in the IDOAC group. The mean $\mathrm{CHA}_{2} \mathrm{DS}_{2}-\mathrm{VASc}$ score was $3.8 \pm 1.7$ and $3.9 \pm 1.3(\mathrm{p}=0.89)$, while the HAS-BLED score was $2.5 \pm 1.0$ and 2.5 $\pm 0.9(\mathrm{p}=0.96)$, in UDOAC and IDOAC groups, respectively. At the time of admission, 14 (10.6\%) patients 
UDOAC

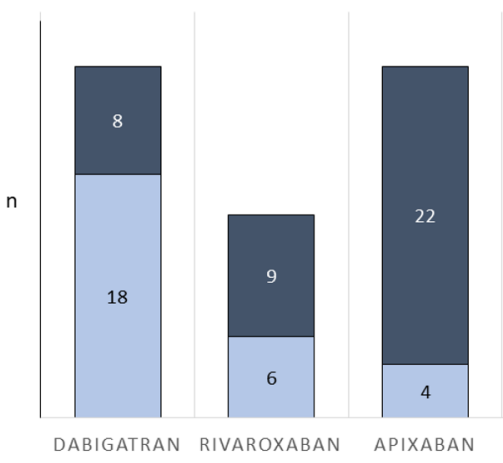

IDOAC

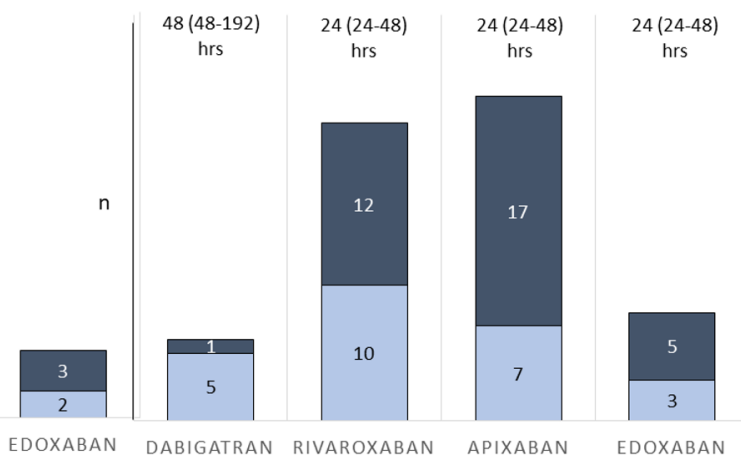

Figure 1 Different types and dosages of DOACs at hospital admission for patients in UDOAC and IDOAC groups and hours of DOAC interruption before PCI in IDOAC group. Dark blue: full dose (150 mg/twice daily dabigatran; $20 \mathrm{mg} / \mathrm{od}$ rivaroxaban; $5 \mathrm{mg} / \mathrm{twice}$ daily apixaban; $60 \mathrm{mg} / \mathrm{od}$ edoxaban); light blue: reduced dose (110 mg/twice daily dabigatran; $15 \mathrm{mg} / \mathrm{once}$ daily rivaroxaban; $2.5 \mathrm{mg} / \mathrm{twice}$ daily apixaban; $30 \mathrm{mg} /$ odonce daily edoxaban). DOAC, direct oral anticoagulant; IDOAC, interrupted direct oral anticoagulant; $\mathrm{PCI}$, percutaneous coronary intervention; UDOAC, uninterrupted direct oral anticoagulant.

were receiving acetylsalicylic acid (ASA) and $5(3.8 \%$ ) a dual antiplatelet therapy (DAPT), in addition to a DOAC.

\section{Antithrombotic therapy in the periprocedural period}

The median time from hospital admission to PCI was 9.5 (IQR: 2.0-31.5) hours in UDOAC and 45.5 (IQR: 22.5 to 92.0) hours in IDOAC group $(\mathrm{p}<0.0001)$.

A pretreatment with DAPT was employed in 69 (52.3\%) patients, without differences between the two groups, while low-molecular weight heparins (LMWHs) were used before PCI in $6(8.3 \%)$ of UDOAC and $20(33.3 \%)$ of IDOAC patients $(\mathrm{p}=0.0003)$.

Table 2 shows the angiographic and procedural variables of enrolled patients. A radial approach was used in $92 \%$, a multivessel disease was present in $48 \%$ and a drugeluting stent (DES) was implanted in $98 \%$ of patients, without differences between the two groups. Considering the antithrombotic therapies administered during the PCI, a glycoprotein IIb/IIIa inhibitor was used in 3\% and unfractionated heparin in $66 \%$ of cases (table 2 ).

The rate of any procedural complication (including slow/no flow, coronary dissection, cardiac tamponade, major arrhythmias and access site complications) was lower in the UDOAC compared with IDOAC group ( $2.8 \%$ vs $13.3 \%$; $\mathrm{p}=0.02)$.

The median hospital length of stay was 7 (IQR: 5-9) days in UDOAC and 8 (IQR: 5-13) days in IDOAC group ( $\mathrm{p}=0.14)$. In-hospital incidence of MACE (6.9\% vs $11.7 \%$ ) and NACE $(11.1 \%$ vs $13.3 \%)$ did not differ significantly between UDOAC and IDOAC groups.

At the time of discharge, a triple therapy (DOAC+DAPT) was prescribed in $86.1 \%$ and $83.3 \%(\mathrm{p}=0.66)$, while a dual therapy (DOAC+ASA or P2Y12 inhibitor) in $13.9 \%$ and $11.7 \%$ ( $\mathrm{p}=0.70$ ) of patients included in UDOAC and IDOAC groups, respectively.

\section{Clinical events at follow-up}

Data at follow-up were obtained for all patients included in the present analysis. The median time from hospital entry to 6-month follow-up was 191 (178-199) days.
The rates of MACE (13.9\% vs 16.7\%) and NACE (20.8\% vs $21.7 \%)$ at 6 months were comparable between UDOAC and IDOAC groups (figure 2). The KaplanMeier curves of MACE and NACE in the two groups are shown in figure 3 .

The overall incidence of bleeding events was $13.9 \%$ versus $18.3 \% \quad(\mathrm{p}=0.49)$, while major bleedings (BARC $\geq 3$ ) occurred in $6.9 \%$ versus $6.7 \%(p=1.0)$ of patients in UDOAC and IDOAC groups, respectively.

At multivariable analysis, increasing $\mathrm{CHA}_{2} \mathrm{DS}_{2}-\mathrm{VASc}$ score (HR: $1.39 ; 95 \%$ CIs 1.05 to $1.83 ; \mathrm{p}=0.02$ ) resulted as the only independent predictor of NACE at 6 months from hospital admission.

\section{DISCUSSION}

The present analysis, including a nationwide, contemporary, real-world cohort of patients with concomitant ACS and AF, suggests that $\mathrm{PCI}$ is a safe procedure during UDOAC.

Although risks of major bleeding events with PCI procedures are relatively low, management of bleeding complications associated with oral anticoagulants can be challenging even with DOACs that, unlike vitamin $\mathrm{K}$ antagonists, present the advantage of having reversal agents available in clinical practice. ${ }^{3}$ In our series, major bleeding events, classified with a universal and contemporary definition, occurred in approximately $7 \%$ of cases within the first 6 months from hospital admission, being managed without the employment of reversal agents for DOACs.

In 2017, the ACC released an expert consensus document on the periprocedural management of anticoagulation in patients with non-valvular AF to provide guidance on DOAC interruption before invasive procedures. ${ }^{4}$ Considering the different pharmacokinetics of DOACs, the timing for interruption varied for dabigatran based on eGFR and was uniform for other DOACs, in accordance with prescribing information. ${ }^{4}{ }^{12}$ In addition, the consensus states that in the absence of electrical or 
Table 1 Clinical characteristics, haemodynamic variables, laboratory parameters and antithrombotic therapies in addition to DOACs at baseline

\begin{tabular}{|c|c|c|c|}
\hline & $\begin{array}{l}\text { UDOAC } \\
n=72\end{array}$ & $\begin{array}{l}\text { IDOAC } \\
n=60\end{array}$ & $P$ value \\
\hline Age, years (mean $\pm S D)$ & $74 \pm 9$ & $78 \pm 8$ & 0.04 \\
\hline Males, n (\%) & $53(73.6)$ & $43(71.7)$ & 0.80 \\
\hline STEMI, n (\%) & $30(41.7)$ & $8(13.3)$ & 0.0003 \\
\hline Body mass index (mean \pm SD) & $27.7 \pm 4.7$ & $27.7 \pm 4.6$ & 0.95 \\
\hline Active smokers, $\mathrm{n}(\%)$ & $10(13.9)$ & $7(11.7)$ & 0.58 \\
\hline Diabetes mellitus, n (\%) & $25(34.7)$ & $25(41.7)$ & 0.41 \\
\hline Hypertension, n (\%) & $64(88.9)$ & $51(85.0)$ & 0.51 \\
\hline Hypercholesterolaemia, n (\%) & $42(58.3)$ & $34(56.7)$ & 0.16 \\
\hline Peripheral artery disease, $\mathrm{n}(\%)$ & $11(15.3)$ & $4(6.7)$ & 0.21 \\
\hline Previous stroke/TIA, n (\%) & $18(25.0)$ & $9(15.0)$ & 0.16 \\
\hline History of heart failure, $\mathrm{n}(\%)$ & $14(19.4)$ & $10(16.7)$ & 0.68 \\
\hline Prior MI, n (\%) & $22(30.6)$ & $19(31.7)$ & 0.89 \\
\hline Previous PCI/CABG, n (\%) & $28(38.9)$ & $22(36.7)$ & 0.79 \\
\hline History of major bleeding, n (\%) & $3(4.2)$ & $2(3.3)$ & 0.80 \\
\hline Chronic kidney disease, n (\%) & $19(26.4)$ & $11(18.3)$ & 0.54 \\
\hline $\mathrm{CHA}_{2} \mathrm{DS}_{2}-\mathrm{VASc}($ mean $\pm \mathrm{SD})$ & $3.8 \pm 1.7$ & $3.9 \pm 1.3$ & 0.89 \\
\hline HAS BLEED (mean $\pm S D)$ & $2.5 \pm 1.0$ & $2.5 \pm 0.9$ & 0.96 \\
\hline Ejection fraction, \% (mean $\pm S D)$ & $47.4 \pm 9.7$ & $45.1 \pm 12.5$ & 0.40 \\
\hline eGFR, mL/min (mean $\pm S D$ ) & $68.4 \pm 26.7$ & $63.5 \pm 23.3$ & 0.25 \\
\hline Haemoglobin, g/dL (mean \pm SD) & $13.0 \pm 1.8$ & $12.9 \pm 1.5$ & 0.69 \\
\hline Creatinine, mg/dL (mean $\pm S D)$ & $1.1 \pm 0.3$ & $1.1 \pm 0.3$ & 0.72 \\
\hline Platelets, $10^{5} / \mathrm{mL}$ (mean $\pm S D$ ) & $225.8 \pm 75.5$ & $207.9 \pm 75.4$ & 0.19 \\
\hline ASA only, n (\%) & $7(9.7)$ & 7 (11.7) & 0.72 \\
\hline P2Y12 inhibitors only, n (\%) & $3(4.2)$ & $3(5.0)$ & 1.0 \\
\hline Dual antiplatelet therapy, $\mathrm{n}(\%)$ & $3(4.2)$ & $2(3.3)$ & 1.0 \\
\hline
\end{tabular}

AF, atrial fibrillation; ASA, acetylsalicylic acid; CABG, coronary artery bypass grafting; DOACs, direct oral anticoagulants; eGFR, estimated glomerular filtration rate; HR, heart rate; IDOAC, interrupted direct oral anticoagulant; MI, myocardial infarction; NSTE-ACS, non-ST elevation acute coronary syndromes; $\mathrm{PCI}$, percutaneous coronary intervention; SBP, systolic blood pressure; STEMI, ST-elevation myocardial infarction; TIA, transient ischaemic attack; UDOAC, uninterrupted direct oral anticoagulant.

haemodynamic instability, it is reasonable to wait for the effects of the DOAC to dissipate and then perform the PCI through a radial artery approach. ${ }^{4}$ Later, both the American Heart Association ${ }^{5}$ and the European Heart Rhythm Association ${ }^{6}$ released scientific documents on management of patients on DOACs in the acute care and periprocedural setting. Similarly, they discerned risk based on possible procedural bleeding complications, patient's clinical profile and type of DOAC. ${ }^{56}$

To the best of our knowledge, this is the first study assessing the safety of UDOAC in patients undergoing PCI. Therefore, the recommendations on periprocedural management of DOACs were generated from pharmacokinetic studies and evidence about the effectiveness
Table 2 Angiographic, procedural variables and antithrombotic therapies administered in the cath lab in the two groups

\begin{tabular}{|c|c|c|c|}
\hline & UDOAC $n=72$ & IDOAC $n=60$ & $P$ value \\
\hline Radial approach, n (\%) & $66(91.7)$ & $55(91.7)$ & 1.0 \\
\hline Multivessel disease, n (\%) & $29(40.3)$ & $34(56.7)$ & 0.06 \\
\hline \multicolumn{4}{|l|}{ Site of PCI, $n(\%)$} \\
\hline Left main & $6(8.3)$ & $4(6.7)$ & 0.76 \\
\hline Left anterior descending & $39(54.2)$ & $40(66.7)$ & 0.14 \\
\hline Circumflex & $18(25.0)$ & $15(25.0)$ & 1.0 \\
\hline Ramus intermedius & $7(9.7)$ & $2(3.3)$ & 0.18 \\
\hline Right coronary artery & $26(36.1)$ & $17(28.3)$ & 0.34 \\
\hline Arterial/venous graft & $2(2.8)$ & $2(3.3)$ & 1.0 \\
\hline DES, n (\%) & $72(100)$ & $57(95)$ & 0.09 \\
\hline $\begin{array}{l}\text { Stents implanted/patient, } \\
\text { median (IQR) }\end{array}$ & $1(1-2)$ & $2(1-2)$ & 0.39 \\
\hline GP IIb/llla inhibitors, n (\%) & $4(5.6)$ & 0 & 0.13 \\
\hline Unfractionated heparin, $n(\%)$ & $42(58.3)$ & $45(75.0)$ & 0.04 \\
\hline
\end{tabular}

BMS, bare metal stent; DES, drug-eluting stent; GP IIb/IIla, glycoprotein Ilb/Illa receptor inhibitors; IDOAC, interrupted direct oral anticoagulant; $\mathrm{PCl}$, percutaneous coronary intervention; UDOAC, uninterrupted direct oral anticoagulant.

of vitamin $\mathrm{K}$ antagonists' interruption before elective or urgent PCI. ${ }^{4-6}$ In a retrospective analysis of 523 patients ( $70 \%$ with $\mathrm{AF}$ ) on long-term warfarin therapy referred for PCI in seven Finland centres, major bleeding events were more common in those who interrupted warfarin compared with those who did not. ${ }^{13}$ In a subanalysis of the What is the Optimal antiplElet and anticoagulant therapy in patients with oral anticoagulation and coronary StenTing study, uninterrupted therapy with warfarin was not associated with an increase of bleeding or MACE at 1 year compared with a strategy of warfarin interruption and bridging therapy before PCI. ${ }^{14}$ Accordingly, in a meta-analysis of uninterrupted strategy when compared with interrupted strategy, uninterrupted therapy with warfarin was found to be at least as safe as interrupted oral anticoagulation in patients undergoing coronary angiography with or without PCI. ${ }^{15}$ Moreover, in the Management of patients with Atrial Fibrillation undergoing Coronary Artery Stenting trial, the number of access site bleedings and the length of hospital stay after PCI was higher in patients who interrupted warfarin compared with patients who did not interrupt anticoagulation therapy. ${ }^{16} \mathrm{~A}$ high incidence of procedural complications, including access site bleedings and a prolonged time to PCI were also seen in our cohort of patients on long-term DOACs.

Since DOAC regimens became available for clinical use in AF, few studies have been conducted in order to assess the safety of an UDOAC strategy for cardiac procedures such as pulmonary vein ablation, electrical cardioversion, coronary angiography or elective PCI. ${ }^{2-6} 1718$ In our study, we first demonstrated the safety of UDOAC in ACS using current PCI strategies, as suggested by the use of radial 


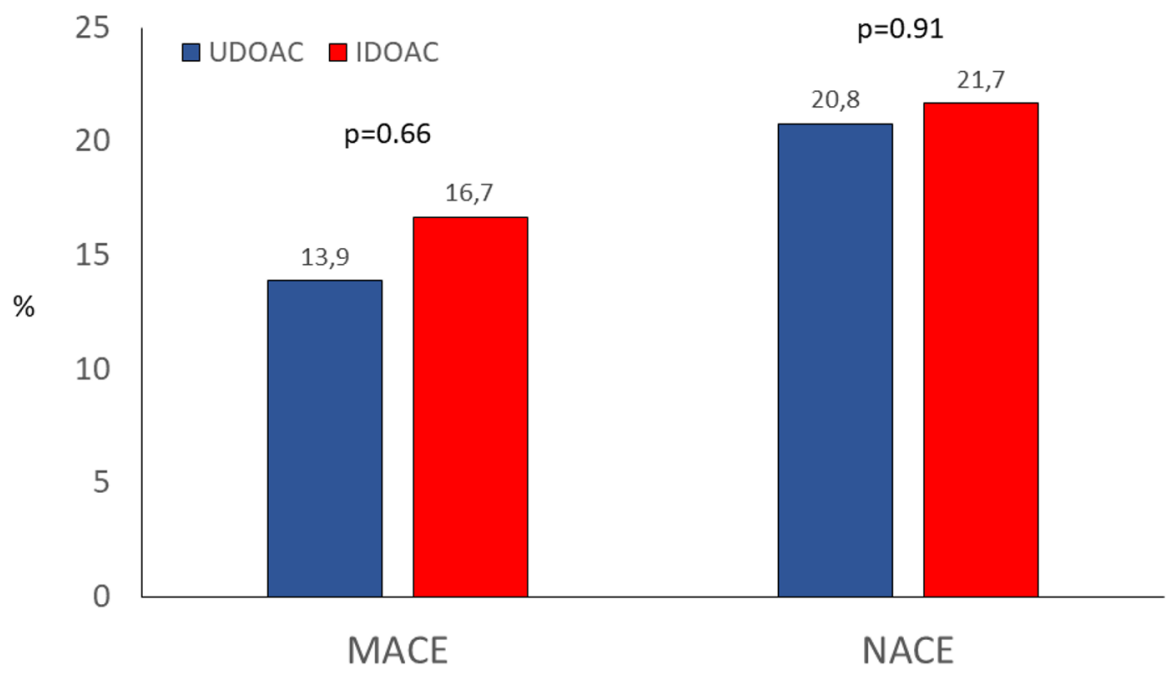

Figure 2 Rates of MACE and NACE at 6 months from hospital entry in UDOAC and IDOAC groups. IDOAC, interrupted direct oral anticoagulant; MACE, major adverse cardiovascular event; NACE, net adverse clinical event; UDOAC, uninterrupted direct oral anticoagulant.

access and DES in nearly the totality of patients enrolled and the scarce rate of glycoprotein IIb/IIIa during the PCI. These measures are recommended by consensus documents and international guidelines ${ }^{2-6}$ in order to reduce the risk of bleeding and minimise the duration of DAPT ${ }^{19} 20$ and may partially explain the comparable risk for bleeding events between UDOAC and IDOAC observed in our analysis. Notably, patients who received PCI during UDOAC were more frequently diagnosed with STEMI resulting in shorter times to PCI and a lower incidence of multivessel coronary artery disease than patients in the IDOAC group. Our findings further corroborate the safety data in terms of bleeding of the UDOAC strategy.

Consensus documents also state that parenteral bridging after DOACs interruption in patients without high thrombosis risk is not indicated due to their short half-lives. ${ }^{4-6}$ This statement has been recently confirmed by the large Perioperative Anticoagulation Use for Surgery Evaluation (PAUSE) trial that recently included about $3000 \mathrm{AF}$ patients on long-term DOACs scheduled for an elective surgery or procedure. ${ }^{21}$ The PAUSE demonstrated that

A

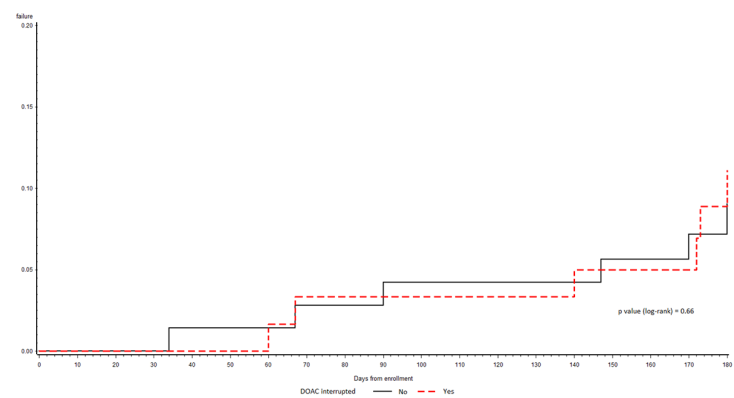

a perioperative management strategy without heparin bridging was associated with low rates of major bleeding and arterial thromboembolism. ${ }^{21}$ Nevertheless, bridging therapies has been largely used even in our series, since one-third of patients in the IDOAC group received an LMWH before PCI. This aspect, together with the need to improve the periprocedural antithrombotic management and outcome, especially in patients on long-term anticoagulation therapy, should deserve specific education campaigns.

\section{Study limitations}

Our study must be evaluated in the light of the known limitations of observational, cross-sectional studies. In addition, even though the participating centres were asked to include in the registry all consecutive ACS patients with AF requiring coronary stents, we were not able to verify the enrolment process due to the absence of administrative auditing. However, based on the number of $\mathrm{AF}$ patients enrolled in previous nationwide registries on ACS, ${ }^{22}$ we believe that the rate of patients enrolled is reliable, and it is unlikely that a selective enrolment in a

B

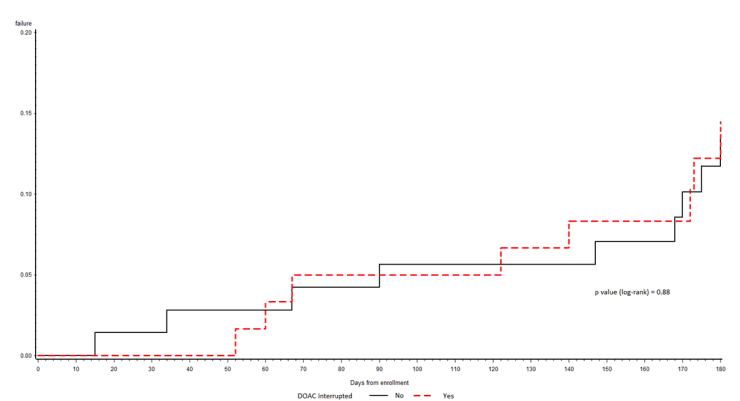

Figure 3 Kaplan-Meier curves of MACE (panel a) and NACE (panel B) at 6 months from hospital entry for patients in UDOAC and IDOAC groups. IDOAC, interrupted direct oral anticoagulant; MACE, major adverse cardiovascular event; NACE, net adverse clinical event; UDOAC, uninterrupted direct oral anticoagulant. 
few sites may have substantially changed the study results. Furthermore, besides the differences in the perioperative use of DOACs, other variables not considered or included in the multivariable analysis on NACE at 6 months may have influenced our results. Finally, our sample size may not be sufficient to cover small but clinically significant differences in bleeding and thrombotic complications between UDOAC and IDOAC strategies, and the sample size is limited for subgroup analyses. In spite of these limitations, we feel that our data may be used to guide the treatment of patients with ACS and concomitant AF on long-term DOAC undergoing PCI.

\section{CONCLUSIONS}

Our study shows that a PCI procedure in ACS is safe during UDOAC, with no excess bleeding complications, as compared with IDOAC. Large, prospective studies are warranted to compare different periprocedural management strategies in ACS patients on long-term DOAC therapy undergoing coronary stenting.

\author{
Author affiliations \\ ${ }^{1}$ Department of Cardiosciences, San Camillo-Forlanini Hospital, Roma, Italy \\ ${ }^{2}$ Department of Cardiology, Ospedale Santa Maria delle Croci, Ravenna, Italy \\ ${ }^{3}$ Department of Cardiology, San Donato Hospital, Arezzo, Italy \\ ${ }^{4}$ Centro Studi ANMCO, Firenze, Italy \\ ${ }^{5}$ Department of Cardiology, San Luca Institute Italian Institute for Auxology, Milano, \\ Italy \\ ${ }^{6}$ Department of Cardiology, Monzino Cardiology Centre, Milano, Italy \\ ${ }^{7}$ Department of Cardiology, Ospedale degli Infermi, Rivoli, Italy \\ ${ }^{8}$ Department of Cardiology, Ospedale San Giovanni Bosco, Torino, Italy \\ ${ }^{9}$ Azienda Sanitaria Universitaria Integrata di Trieste, Trieste, Italy \\ ${ }^{10}$ Deparment of Cardiology, National Centre of Excellence Garibaldi Hospital \\ Garibaldi-Nesima Hospital, Catania, Italy
}

Contributors The Steering Committee designed the study. All authors participated in the conduct of the study and contributed to the interpretation of the results. LDL, $A R$ and $L B$ drafted the manuscript; MU, IM, SMBP, ADL, DG and MMG revised it critically; SB, JC and DL analysed the data.

Funding The authors have not declared a specific grant for this research from any funding agency in the public, commercial or not-for-profit sectors.

Disclaimer The sponsor of the study was the Heart Care Foundation, a non-profit independent organisation, which also owns the database. Database management, quality control of the data and data analyses were under the responsibility of the ANMCO Research Centre of the Heart Care Foundation. The study was partially supported by an unrestricted grant by Boehringer Ingelheim, Pharma GmbH \& CoKG. No compensations were provided to participating sites, investigators nor members of the Steering Committee. The Steering Committee of the study had full access to all the data in this study and takes complete responsibility for the integrity of the data and the accuracy of the data analysis.

Competing interests LDL and AR report lecture fees from Bayer, Boehringer Ingelheim, Daiichi Sankyo and Pfizer/BMS outside the submitted work; all other authors have reported that no potential conflicts of interest exist with any companies/organisations whose products or services may be discussed in this article. DL is an employee of Heart Care Foundation, which conducted the study with an unrestricted grant of research from Boehringer Ingelheim and Pharma GmbH \& CoKG.

Patient consent for publication Not required.

Ethics approval Local Institutional Review Boards (IRB) approved the study protocol according to the current Italian rules. The IRB of the coordinator center (A.O. San Camillo - Forlanini) approved the study on 24 January 2018 (reference number: 151/CS).

Provenance and peer review Not commissioned; externally peer reviewed.
Data availability statement Data are available on reasonable request.

Author note See online supplementary appendix 1 for a complete list of centres and investigators.

Open access This is an open access article distributed in accordance with the Creative Commons Attribution Non Commercial (CC BY-NC 4.0) license, which permits others to distribute, remix, adapt, build upon this work non-commercially, and license their derivative works on different terms, provided the original work is properly cited, appropriate credit is given, any changes made indicated, and the use is non-commercial. See: http://creativecommons.org/licenses/by-nc/4.0/.

ORCID iD

Leonardo De Luca http://orcid.org/0000-0002-8552-1272

\section{REFERENCES}

1 Capodanno D, Huber K, Mehran R, et al. Management of Antithrombotic Therapy in Atrial Fibrillation Patients Undergoing PCl: JACC State-of-the-Art Review. J Am Coll Cardiol 2019;74:83-99.

2 Lip GYH, Collet J-P, Haude M, et al. 2018 joint European consensus document on the management of antithrombotic therapy in atrial fibrillation patients presenting with acute coronary syndrome and/ or undergoing percutaneous cardiovascular interventions: a joint consensus document of the European Heart Rhythm Association (EHRA), European Society of Cardiology Working Group on Thrombosis, European Association of Percutaneous Cardiovascular Interventions (EAPCI), and European Association of Acute Cardiac Care (ACCA) endorsed by the Heart Rhythm Society (HRS), AsiaPacific Heart Rhythm Society (APHRS), Latin America Heart Rhythm Society (LAHRS), and Cardiac Arrhythmia Society of Southern Africa (CASSA). Europace 2019;21:192-3.

3 January CT, Wann LS, Calkins H, et al. 2019 AHA/ACC/HRS focused update of the 2014 AHA/ACC/HRS guideline for the management of patients with atrial fibrillation: a report of the American College of Cardiology/American heart association Task force on clinical practice guidelines and the heart rhythm society in collaboration with the Society of thoracic surgeons. Circulation 2019;140:e125-51.

4 Doherty JU, Gluckman TJ, Hucker WJ, et al. 2017 ACC expert consensus decision pathway for periprocedural management of anticoagulation in patients with nonvalvular atrial fibrillation: a report of the American College of Cardiology Clinical Expert Consensus Document Task Force. J Am Coll Cardiol 2017;69:871-98.

5 Raval AN, Cigarroa JE, Chung MK, et al. Management of patients on non-vitamin $\mathrm{K}$ antagonist oral anticoagulants in the acute care and periprocedural setting: a scientific statement from the American Heart Association. Circulation 2017;135:e604-33.

6 Steffel J, Verhamme P, Potpara TS, et al. The 2018 European Heart Rhythm Association practical guide on the use of non-vitamin $\mathrm{K}$ antagonist oral anticoagulants in patients with atrial fibrillation. Eur Heart J 2018;39:1330-93.

7 De Luca L, Rubboli A, Bolognese L, et al. Antithrombotic management of patients with acute coronary syndrome and atrial fibrillation undergoing coronary stenting: a prospective, observational, nationwide study. BMJ Open 2020;10:e041044.

8 De Luca L, Di Lenarda A, Rubboli A, et al. Post-Discharge antithrombotic management and clinical outcomes of patients with new-onset or pre-existing atrial fibrillation and acute coronary syndromes undergoing coronary stenting: follow-up data of the MATADOR-PCI study. Eur J Intern Med 2021;88:28-34.

9 D'Souza G, Viscusi ER, Rowlands J. Use of Cockroft and Gault formula for estimation of creatinine clearance. Anesthesiology 2008;109:1140-1.

10 Thygesen K, Alpert JS, Jaffe AS, et al. Third universal definition of myocardial infarction. J Am Coll Cardiol 2012;60:1581-98.

11 Mehran R, Rao SV, Bhatt DL, et al. Standardized bleeding definitions for cardiovascular clinical trials: a consensus report from the bleeding academic research Consortium. Circulation 2011;123:2736-47.

12 Lip GYH, Lane DA. Assessing bleeding risk in atrial fibrillation with the HAS-BLED and ORBIT scores: clinical application requires focus on the reversible bleeding risk factors. Eur Heart $J$ 2015;36:ehv415-3267.

13 Karjalainen PP, Vikman S, Niemelä M, et al. Safety of percutaneous coronary intervention during uninterrupted oral anticoagulant treatment. Eur Heart J 2008;29:1001-10.

14 Dewilde WJM, Janssen PW, Kelder JC, et al. Uninterrupted oral anticoagulation versus bridging in patients with long-term oral anticoagulation during percutaneous coronary intervention: subgroup analysis from the WOEST trial. Eurolntervention 2015;11:381-90. 
15 Kowalewski M, Suwalski P, Raffa GM, et al. Meta-analysis of uninterrupted as compared to interrupted oral anticoagulation with or without bridging in patients undergoing coronary angiography with or without percutaneous coronary intervention. Int $J$ Cardiol 2016;223:186-94

16 Kiviniemi T, Airaksinen KEJ, Rubboli A, et al. Bridging therapy with low molecular weight heparin in patients with atrial fibrillation undergoing percutaneous coronary intervention with stent implantation: the AFCAS study. Int J Cardiol 2015;183:105-10.

17 Vranckx P, Verheugt FWA, de Maat MP, et al. A randomised study of dabigatran in elective percutaneous coronary intervention in stable coronary artery disease patients. Eurolntervention 2013;8:1052-60.

18 Vranckx P, Leebeek FWG, Tijssen JGP, et al. Peri-procedural use of rivaroxaban in elective percutaneous coronary intervention to treat stable coronary artery disease. The X-PLORER trial. Thromb Haemost 2015;114:258-67.

19 Lahtela H, Karjalainen PP, Niemelä M, et al. Are glycoprotein inhibitors safe during percutaneous coronary intervention in patients on chronic warfarin treatment? Thromb Haemost 2009;102:1227-33.

20 Pancholy SB, Ahmed I, Bertrand OF, et al. Frequency of radial artery occlusion after transradial access in patients receiving warfarin therapy and undergoing coronary angiography. Am J Cardiol 2014;113:211-4.

21 Douketis JD, Spyropoulos AC, Duncan J, et al. Perioperative management of patients with atrial fibrillation receiving a direct oral anticoagulant. JAMA Intern Med 2019;179:1469-78.

22 De Luca L, Casella G, Rubboli A, et al. Recent trends in management and outcome of patients with acute coronary syndromes and atrial fibrillation. Int J Cardiol 2017;248:369-75. 